\title{
A Case of Horner's Syndrome following Ultrasound-Guided Infraclavicular Brachial Plexus Block
}

\author{
Trabelsi Walid, Belhaj Amor Mondher, Lebbi Mohamed Anis, and Ferjani Mustapha
}

Departement of Anesthesia and Intensive Care Unit, Tunisian Military Hospital, 1002 Tunis, Tunisia

Correspondence should be addressed to Trabelsi Walid, walid_trabelsi2009@yahoo.fr

Received 13 June 2012; Accepted 7 August 2012

Academic Editors: I.-O. Lee and D. A. Story

Copyright () 2012 Trabelsi Walid et al. This is an open access article distributed under the Creative Commons Attribution License, which permits unrestricted use, distribution, and reproduction in any medium, provided the original work is properly cited.

Horner's syndrome results from paralysis of the ipsilateral sympathetic cervical chain (stellate ganglion) caused by surgery, drugs (mainly high concentrations of local anesthetics), local compression (hematoma or tumor), or inadequate perioperative positioning of the patient. It occurs in $100 \%$ of the patients with an interscalene block of the brachial plexus and can also occur in patients with other types of supraclavicular blocks.In this case report, we presented a case of Horner's syndrome after performing an ultrasound-guided infraclavicular brachial plexus block with $15 \mathrm{~mL}$ of bupivacaine $0.5 \%$. It appeared 40 minutes after the block with specific triad (ptosis, miosis, and exophtalmia) and quickly disappears within 2 hours and a half without any sequelae. Horner's syndrome may be described as an unpleasant side effect because it has no clinical consequences in itself. For this reason anesthesiologists should be aware of this syndrome, and if it occurs patients should be reassured and monitored closely.

\section{Introduction}

Horner's syndrome may correspond to a diffusion of local anesthetics in prevertebral spaces ultimately involving the sympathetic nerves and communicating with cervical nerve trunks [1]. It results from paralysis of the ipsilateral sympathetic cervical chain (stellate ganglion) caused by surgery, drugs (mainly high concentrations of local anesthetics), local compression (hematoma or tumor), or inadequate perioperative positioning of the patient $[2,3]$.

Interscalene and supraclavicular blocks of the brachial plexus are the main anesthetic techniques associated with this syndrome [4-6].

\section{Case Report}

After her written consent, a 52-year-old healthy woman $(74 \mathrm{~kg}, 168 \mathrm{~cm})$, classified as American Society of Anesthesiologists physical status I (with a medical history of subtotal thyroidectomy under cervicotomy), was scheduled for carpal tunnel syndroms surgery under tourniquet device. Perioperative anesthesia consisted of an ultrasound-guided infraclavicular brachial plexus block. No premedications were applied to the case. An intravenous cannula was inserted into the contralateral arm, and a continuous infusion (crystalloid solution) was started. For the whole procedure the patient was routinely monitored with electrocardiogram (ECG), noninvasive blood pressure (NIBP) measurement, and pulse oximetry (SpO2).

The patient was in supine position, with the head facing away from the side to be anesthetized, and the arm were adducted and flexed at the elbow and resting over the chest or upper abdomen. Following the positioning, the area on the infraclavicular region to be operated was disinfected. A 10to $12-\mathrm{MHz}$ linear probe (Logiq 7 GE Health care, USA) was placed in the deltopectoral groove. Under sterile conditions and after subcutaneous infiltration, a $22 \mathrm{G}$ insulated needle (Echoplex D $50 \mathrm{~mm}$, Vygon, France) was inserted and advanced using in-plane needle-probe alignment. Injection of local anesthetic selectively surrounded each sonographically imaged brachial plexus cord with approximately $5 \mathrm{~mL}$ of $0.5 \%$ bupivacaine.

Block onset time was 15 minutes. There was no change in vital parameters. 40 minutes after block performance (and 10 minutes after beginning of surgery) the Horner's syndrome was observed. The patient did not have any respiratory difficulty. Surgery was completed successfully without any 
complication. Horner's syndrome vanished approximately two hours and a half later.

\section{Discussion}

This case report is the first in the literature to describe a Horner's syndrome after ultrasound-guided infraclavicular brachial plexus block.

Jandard et al. [7] reported a Horner's syndrome rate of 4\%, Kilka et al. [8] 7\%, Rettig et al. [9] 12\%, and Neuburger et al. [10] 1\%. There may be many causes of Horner's syndrome. It may be related to distribution of local anesthetic solution. There are different studies about distribution of local anesthetics and anatomy of the brachial plexus. Rodríguez et al. [11] found that local anesthetics, after both supraclavicular and interscalene blocks, were distributed above and below the clavicle, and conversely they found that after a coracoid block, local anesthetics remained below the clavicle in all patients.

Winnie [12] suggests that the brachial plexus is completely encased in a continuous tubular sheath from the interscalene groove to the axilla. On the other hand Beck et al. [13] showed, in an anatomical study, that connective tissue thickening could divide the neurovascular space of the brachial plexus into two compartments, possibly explaining the unidirectional spreading from the supraclavicular space to the infraclavicular space.

Horner's syndrome can be observed during continuous infusion or with a single large volume. Salengros et al. [14] observed delayed Horner's syndrome in a case during a continuous infusion through a catheter with infraclavicular block approximately 50 hours after the initial block. But Ilfeld et al. [15] published a series that examined patients managed with continuous postoperative infraclavicular local anesthetic infusion. They did not report any signs of Horner's syndrome.

Causes of Horner's syndrome are large accumulation of local anesthetic solution or the atypical proximal migration of the solution above the clavicle toward the supraclavicular paravertebral area. Sometimes Horner's syndrome can be observed without catheter placement, above $40 \mathrm{~mL}$ volumes $[7,8]$. In our case, we think that history of cervicotomy may be responsible for this atypical syndrome caused by anatomical changes in local anesthetic diffusion space, not its volume.

When the rates of complications between the supraclavicular and infraclavicular approaches are compared impairment in diaphragmatic movements can apparently be rated as $100 \%$ for interscalene, $50 \%$ to $77 \%$ for supraclavicular, $24 \%$ to $26 \%$ for proximal infraclavicular and $0 \%$ for more distal infraclavicular blocks $[4,6,9,11]$. According to Rettig et al. [9], Horner's syndrome is a clinically significant sign $(100 \%)$ that predicts changes in hemidiaphragmatic movement; however, in their patients, changes in hemidiaphragmatic movement weres also observed without Horner's syndrome. They suggested that the phrenic nerve and sympathetic trunk are more separated. We did not observe altered respiratory functions or dysphonia in our patient.
Although Horner's syndrome had no clinical consequences to this patient, it may be described as an unpleasant side effect. It has the potential to lead to patient anxiety, discomfort, and dissatisfaction. For this reason anesthesiologists should be aware of this syndrome, and if it occurs, patients should be reassured and monitored closely.

\section{Acknowledgment}

This paper was funded by Tunisian military Hospital.

\section{Conflict of Interests}

The authors declare that they have no conflict of interests.

\section{References}

[1] M. Honma, G. Murakami, T. J. Sato, and A. Namiki, "Spread of injectate during C6 stellate ganglion block and fascial arrangement in the prevertebral region: an experimental study using donated cadavers," Regional Anesthesia and Pain Medicine, vol. 25, no. 6, pp. 573-583, 2000.

[2] T. Vester-Andersen, C. Christiansen, and A. Hansen, "Interscalene brachial plexus block: area of analgesia, complications and blood concentrations of local anesthetics," Acta Anaesthesiologica Scandinavica, vol. 25, no. 2, pp. 81-84, 1981.

[3] R. Hickey, T. A. Garland, and S. Ramamurthy, "Subclavian perivascular block: influence of location of paresthesia," Anesthesia and Analgesia, vol. 68, no. 6, pp. 767-771, 1989.

[4] W. F. Urmey, K. H. Talts, and N. E. Sharrock, "One hundred percent incidence of hemidiaphragmatic paresis associated with interscalene brachial plexus anesthesia as diagnosed by ultrasonography," Anesthesia and Analgesia, vol. 72, no. 4, pp. 498-503, 1991.

[5] P. H. K. Mak, M. G. Irwin, C. G. C. Ooi, and B. F. M. Chow, "Incidence of diaphragmatic paralysis following supraclavicular brachial plexus block and its effect on pulmonary function," Anaesthesia, vol. 56, no. 4, pp. 352-356, 2001.

[6] J. M. Neal, J. M. Moore, D. J. Kopacz, S. S. Liu, D. J. Kramer, and J. J. Plorde, "Quantitative analysis of respiratory, motor, and sensory function after supraclavicular block," Anesthesia and Analgesia, vol. 86, no. 6, pp. 1239-1244, 1998.

[7] C. Jandard, M. E. Gentili, F. Girard et al., "Infraclavicular block with lateral approach and nerve stimulation: extent of anesthesia and adverse effects," Regional Anesthesia and Pain Medicine, vol. 27, no. 1, pp. 37-42, 2002.

[8] H. G. Kilka, P. Geiger, and H. H. Mehrkens, "Infraclavicular vertical brachial plexus blockade. A new technique of regional anaesthesia," Anaesthesist, vol. 44, no. 5, pp. 339-344, 1995.

[9] H. C. Rettig, M. J. M. Gielen, E. Boersma, J. Klein, and G. J. Groen, "Vertical infraclavicular block of the brachial plexus: effects on hemidiaphragmatic movement and ventilatory function," Regional Anesthesia and Pain Medicine, vol. 30, no. 6, pp. 529-535, 2005.

[10] M. Neuburger, H. Kaiser, I. Rembold-Schuster, and H. Landes, "Vertical infraclavicular block of brachial plexus - a clinical study to the reliability of a new method for plexus anaesthesia of the upper extremity," Anaesthesist, vol. 47, no. 7, pp. 595$599,1998$.

[11] J. Rodríguez, M. Bárcena, and J. Álvarez, "Restricted infraclavicular distribution of the local anesthetic solution after 
infraclavicular brachial plexus block," Regional Anesthesia and Pain Medicine, vol. 28, no. 1, pp. 33-36, 2003.

[12] A. P. Winnie, "Interscalene brachial plexus block," Anesthesia and Analgesia, vol. 49, no. 3, pp. 455-466, 1970.

[13] H. Beck, J. S. Esch, A. Dziadzka, and W. Lierse, "The dual compartment construction of the brachial plexus sheath: an anatomical study and its clinical implications," Regional Anesthesia and Pain Medicine, vol. 15, article 47, 1990.

[14] J. C. Salengros, C. Jacquot, A. Hesbois, A. Vandesteene, E. Engelman, and P. Pandin, "Delayed Horner's syndrome during a continuous infraclavicular brachial plexus block," Journal of Clinical Anesthesia, vol. 19, no. 1, pp. 57-59, 2007.

[15] B. M. Ilfeld, T. E. Morey, and F. K. Enneking, "Infraclavicular perineural local anesthetic infusion, a comparison of three dosing regimens for postoperative analgesia," Anesthesiology, vol. 100, no. 2, pp. 395-402, 2004. 


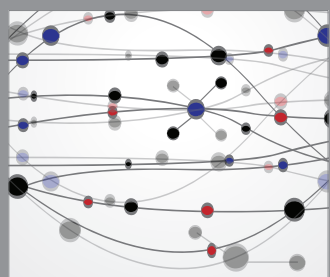

The Scientific World Journal
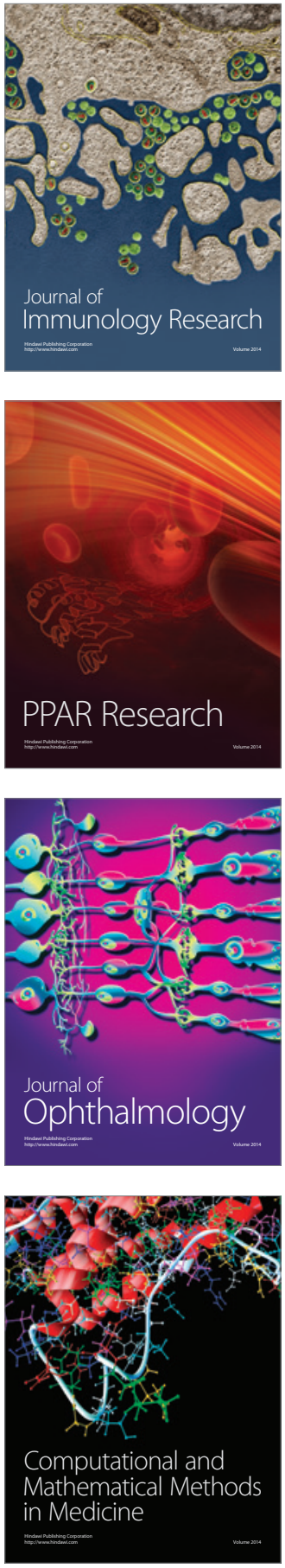

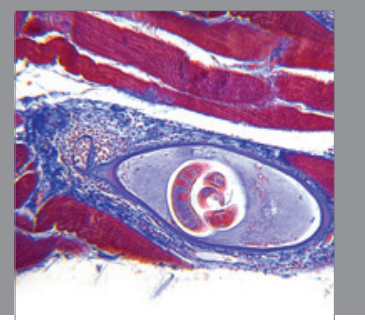

Gastroenterology

Research and Practice
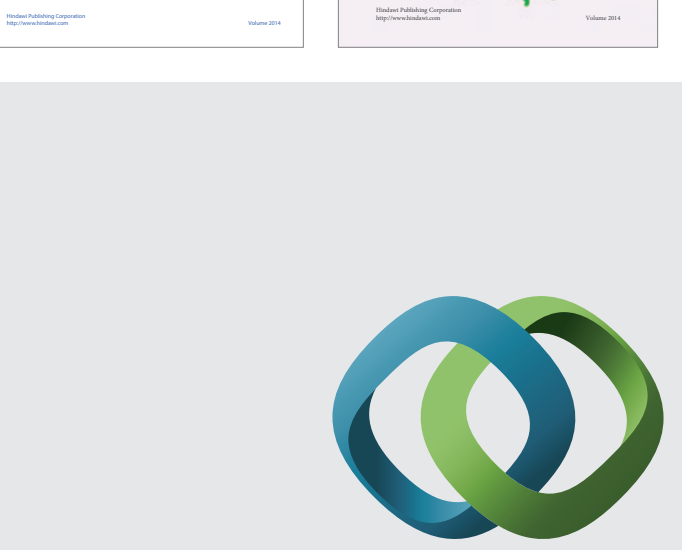

\section{Hindawi}

Submit your manuscripts at

http://www.hindawi.com
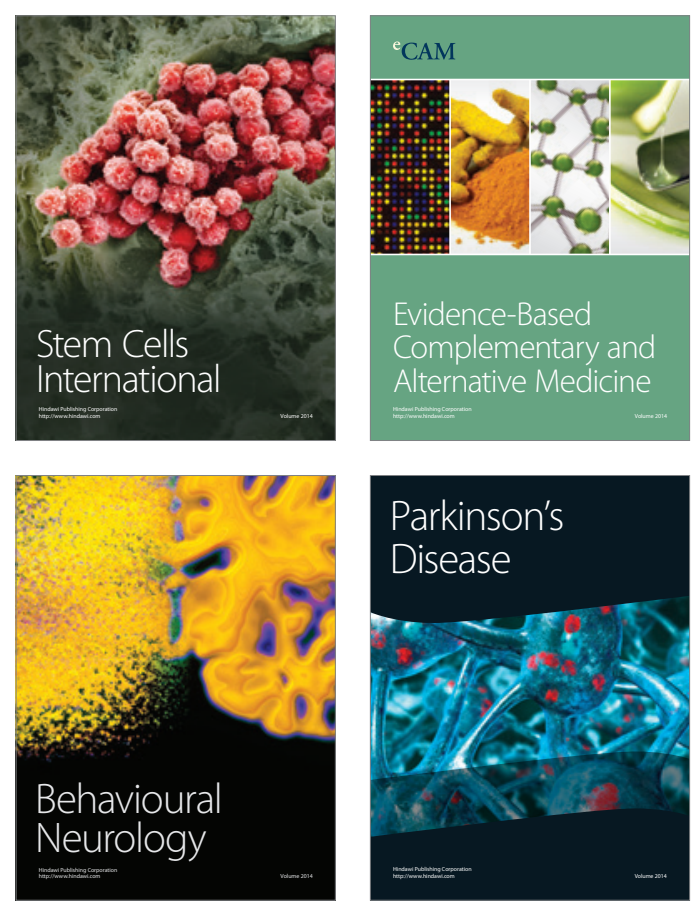

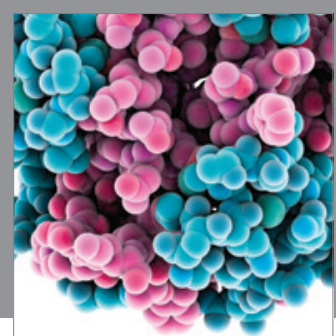

Journal of
Diabetes Research

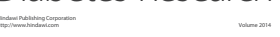

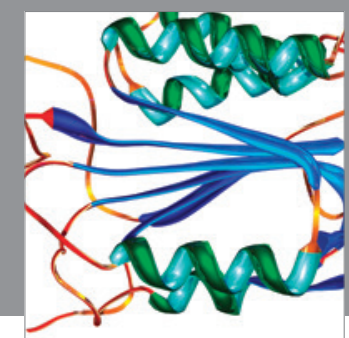

Disease Markers
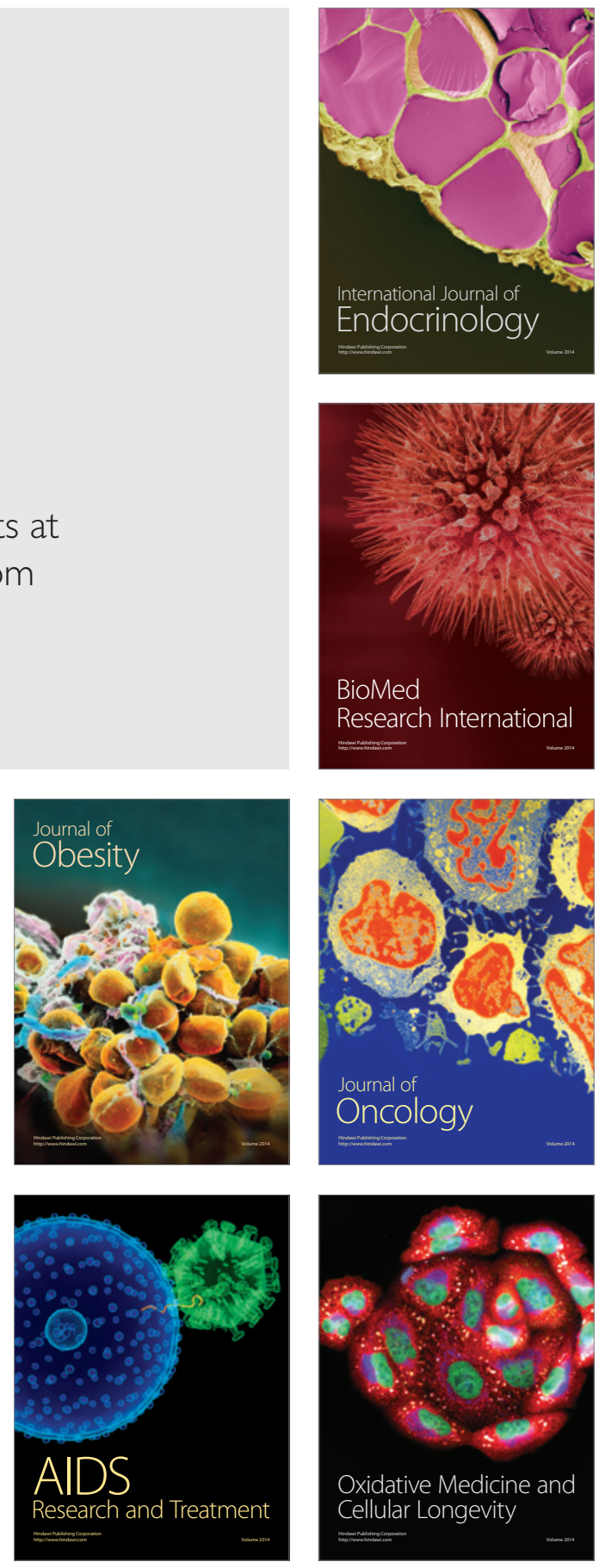